\title{
The Contribution of Activity-Dependent Synaptic Plasticity to Classical Conditioning in Aplysia
}

\author{
Igor Antonov, ${ }^{1}$ Irina Antonova, ${ }^{1}$ Eric R. Kandel, ${ }^{1,2,3}$ and Robert D. Hawkins ${ }^{1,2}$ \\ ${ }^{1}$ Center for Neurobiology and Behavior, College of Physicians and Surgeons, Columbia University, ${ }^{2}$ New York State \\ Psychiatric Institute, and ${ }^{3}$ Howard Hughes Medical Institute, New York, New York 10032
}

Plasticity at central synapses has long been thought to be the most likely mechanism for learning and memory, but testing that idea experimentally has proven to be difficult. For this reason, we have developed a simplified preparation of the Aplysia siphon withdrawal reflex that allows one to examine behavioral learning and memory while simultaneously monitoring synaptic connections between individual identified neurons in the CNS. We previously found that monosynaptic connections from LE siphon sensory neurons to LFS siphon motor neurons make a substantial contribution to the reflex in the siphon withdrawal preparation (Antonov et al., 1999a). We have now used that preparation to assess the contribution of various cellular mechanisms to classical conditioning of the reflex with a siphon tap conditioned stimulus (CS) and tail shock unconditioned stimulus (US). We find that, compared with unpaired training, paired training with the CS and US produces greater enhancement of siphon withdrawal and evoked firing of LFS neurons, greater facilitation of the complex PSP elicited in an LFS neuron by the siphon tap, and greater facilitation of the monosynaptic PSP elicited by stimulation of a single LE neuron. Moreover, the enhanced facilitation of monosynaptic LE-LFS PSPs is greater for LE neurons that fire during the siphon tap and correlates significantly with the enhancement of siphon withdrawal and evoked firing of the LFS neurons. These results provide the most direct evidence to date that activitydependent plasticity at specific central synapses contributes to behavioral conditioning and support the idea that synaptic plasticity is a mechanism of learning and memory more generally.

Key words: Aplysia; classical conditioning; synaptic plasticity; learning; siphon withdrawal; monosynaptic PSP
Since the writings of Ramon y Cajal (1911) and Sherrington (1906) nearly 100 years ago, plasticity at synapses in the CNS has been thought to be the most likely mechanism for learning and memory. However, testing that idea experimentally has proven to be extremely difficult, primarily because of the immense complexity of the mammalian CNS. Thus, although studies on mammalian systems have provided support for the idea that synaptic plasticity contributes to learning (Mayford et al., 1996; Tsien et al., 1996; Rogan et al., 1997), the evidence has been somewhat inconsistent (Zamanillo et al., 1999), perhaps because there is not a direct relationship between changes at specific synapses and behavior (Hawkins, 1997). For this reason, invertebrate preparations such as Aplysia are advantageous, and previous studies have suggested that plasticity at sensory neuron-motor neuron synapses contributes to several simple forms of learning in Aplysia (for review, see Carew and Sahley, 1986; Byrne, 1987; Hawkins et al., 1993).

The Aplysia gill and siphon withdrawal reflex undergoes several nonassociative forms of learning, such as habituation and sensitization, as well as an associative form of learning, classical conditioning (Carew et al., 1981). Conditioning of the withdrawal

Received Feb. 28, 2001; revised May 30, 2001; accepted May 30, 2001.

This research was supported by National Institute of Mental Health Grant MH26212. We thank J. Koester, I. Kupfermann, and M. Rogan for their comments, H. Ayers and M. Pellan for typing this manuscript, and C. Lam for help with the figures.

Correspondence should be addressed to Dr. Robert D. Hawkins, Center for Neurobiology and Behavior, Columbia University College of Physicians and Surgeons, 1051 Riverside Drive, New York, NY 10032. E-mail: rhawkins@ pi.cpmc.columbia.edu.

Copyright (C) 2001 Society for Neuroscience $\quad 0270-6474 / 01 / 216413-\bullet \$ 15.00 / 0$ reflex has many of the behavioral features characteristic of conditioning in mammals, including stimulus specificity (Carew et al., 1983), response specificity (Hawkins et al., 1989; Walters, 1989), temporal specificity and effects of contingency (Hawkins et al., 1986), as well as several effects of context (Colwill et al., 1988a,b) and both forward and simultaneous second-order conditioning (Hawkins et al., 1998). These behavioral results suggest that conditioning in Aplysia and in mammals may share common cellular and molecular mechanisms. Cellular studies in the isolated nervous system of Aplysia have shown that monosynaptic connections between sensory and motor neurons that contribute to the reflex exhibit an analog of conditioning with temporal parameters similar to the behavioral conditioning (Hawkins et al., 1983; Walters and Byrne, 1983; Carew et al., 1984; Clark et al., 1994; Murphy and Glanzman, 1996, 1997, 1999). Moreover, studies of those synapses in isolated cell culture have revealed that they undergo two different types of activity-dependent, associative plasticity that could contribute to the conditioning: enhancement of presynaptic facilitation (Eliot et al., 1994; Bao et al., 1998) and Hebbian long-term potentiation (Lin and Glanzman, 1994a,b, 1997; Bao et al., 1997).

However, these studies in the isolated nervous system or in culture have not been able to address the contribution of the cellular mechanisms to behavioral conditioning. Furthermore, studies of simplified gill withdrawal preparations have suggested that other sites and mechanisms of plasticity might also contribute (Lukowiak, 1986; Colebrook and Lukowiak, 1988; Lukowiak and Colebrook, 1988), so that the contribution of each mechanism has remained uncertain. To address these issues, we developed a simplified preparation consisting of the siphon, tail, and CNS of 
Aplysia that allows one to examine behavior while simultaneously monitoring synaptic connections between identified neurons in the CNS (Antonov et al., 1999a). We have now used that preparation to assess the contribution of activity-dependent synaptic plasticity and other cellular mechanisms to classical conditioning of the siphon withdrawal reflex.

\section{MATERIALS AND METHODS}

The experimental preparation (Fig. 1A) has been described previously (Antonov et al., 1999a). Briefly, the siphon tail and CNS of Aplysia californica (100-150 gm; Marinus, Long Beach, CA) were dissected out in $50 \% \mathrm{MgCl}_{2}$ and $50 \%$ artificial seawater and then pinned to the floor of a recording chamber filled with circulating, aerated artificial seawater at room temperature. The siphon was partially split, and one-half was left unpinned. In electrophysiological experiments, the abdominal ganglion was partially desheathed, and double-barreled microelectrodes (filled with $2.5 \mathrm{M} \mathrm{KCl}$ ) were inserted in an LE siphon sensory neuron (Byrne et al., 1974) and an LFS siphon motor neuron (Frost and Kandel, 1995) for intracellular stimulation and recording.

The conditioned stimulus (CS; a tap of $\sim 20 \mathrm{gm} / \mathrm{mm}^{2}, 500 \mathrm{msec}$ duration, produced by a controlled force stimulator; Cohen et al., 1997) was delivered to the pinned half of the siphon either within the receptive field of the LE neuron ("on-field") or outside the receptive field of the neuron ("off-field"). Withdrawal of the unpinned half of the siphon was recorded with a low-mass isotonic movement transducer (Harvard Apparatus, South Natick, MA) attached by a silk suture. The peak amplitude of siphon withdrawal and both the amplitude and area of PSPs in the motor neuron were measured using a laboratory interface to a microcomputer and commercially available software (Hilal Associates, Englewood, NJ), which also controlled the stimulation. The unconditioned stimulus (US; an AC electric shock of $25 \mathrm{~mA}, 1 \mathrm{sec}$ duration) was delivered to the tail via a fixed capillary electrode. Preparations were considered unhealthy or damaged and not used if the first shock produced a siphon withdrawal of $<3 \mathrm{~mm}$ (the maximal withdrawal was usually $\sim 7 \mathrm{~mm}$ ).

The preparation rested for at least $1 \mathrm{hr}$ before the beginning of training. There were three blocks of four training trials each, with a $5 \mathrm{~min}$ interval between trials in a block and a 20 min rest between blocks (Fig. $1 B$ ). The response to the CS was measured in a pretest $5 \mathrm{~min}$ before the first block (Pre), in test trials 15 min after each block (T1-T3), and in a final post-test $45 \mathrm{~min}$ after the last block (Post). Experiments were continued only if the siphon withdrawal on the pretest was between 0.5 and $5 \mathrm{~mm}$ and were excluded if there was any visible evidence of damage to the siphon at the end of the experiment. During paired training, the CS began $500 \mathrm{msec}$ before the US on each trial. During unpaired training, the interstimulus interval was $2.5 \mathrm{~min}$. Animals were randomly assigned to the training conditions.

On each test trial in the electrophysiological experiments, we measured the monosynaptic PSP from the LE neuron to the LFS neuron, siphon withdrawal and firing of the LE and LFS neurons evoked by the siphon tap, and the withdrawal produced by direct stimulation of the LFS neuron. In some experiments we hyperpolarized the LFS neuron during the siphon tap and measured the complex PSP instead of evoked LFS firing. In those experiments, we also measured the input resistance of the LE and LFS neurons before the tap. If the LE or LFS neuron was lost before the final post-test, results for measures involving that neuron were not included. The data for each measure were analyzed using two- or three-way ANOVAs with one repeated measure (test), followed by planned comparisons of the experimental groups at each test.

\section{RESULTS}

\section{Classical conditioning of the Aplysia siphon-withdrawal reflex}

We have previously demonstrated habituation, dishabituation, and sensitization in the simplified siphon withdrawal preparation (Antonov et al., 1999a). We now tested classical conditioning by comparing changes in the withdrawal reflex in four groups that received paired training, unpaired training, training with the CS alone, or training with the US alone (Fig. 1). Paired training produced a significant increase in the response to the CS compared with the pretest ( $p<0.01$ on the final post-test). By contrast, training with the US alone produced a smaller and shorter-lasting increase (sensitization) that was not significant with the stimulus parameters used in these studies, and unpaired training produced a slight decrease. Training with the CS alone produced a significant decrease (habituation) so that the effects of paired or unpaired training (which include repeated stimulation with the CS) should be judged in comparison with that habituation as well as with their own pretest scores. The habituation would tend to oppose sensitization produced by the US, and these competing processes might account for the small decrease in responding in the unpaired group. There was a significant overall difference between the four groups $\left(F_{(3,66)}=7.93 ; p<0.001\right)$, and paired training produced a greater enhancement of siphon withdrawal than each of the other training conditions $(p<0.01$ on the final post-test in each case). These results demonstrate classical conditioning of the siphon withdrawal reflex in the simplified preparation.

\section{Increase in evoked firing of LFS siphon motor neurons and LE siphon sensory neurons during classical conditioning}

We next began a cellular analysis of the conditioning by recording evoked firing of an identified $\mathrm{LFS}_{\mathrm{B}}$ siphon motor neuron and an LE siphon sensory neuron in the abdominal ganglion simultaneously with the behavior (Fig. 2). There are 25 LE neurons, of which $\sim 5$ are activated by the CS (Byrne et al., 1974; Hickie et al., 1997), and $4 \mathrm{LFS}_{\mathrm{B}}$ neurons, of which 2 or 3 contribute to the response measured in this preparation (Frost and Kandel, 1995; Antonov et al., 1999a). Previous studies have shown that monosynaptic connections between these two classes of cells mediate approximately one-third of the reflex response in this preparation (Antonov et al., 1999a). The remainder of the response is mediated by other, unidentified sensory neurons (Frost et al., 1997), polysynaptic inputs onto the LFS neurons from excitatory and inhibitory interneurons (Frost and Kandel, 1995), and peripheral motor neurons (Perlman, 1979), which also receive monosynaptic input from the LE neurons (Bailey et al., 1979).

In these experiments, there were two groups that received either paired or unpaired training. Again, paired training produced significantly greater enhancement of siphon withdrawal than unpaired training overall $\left(F_{(1,24)}=17.39 ; p<0.001\right)$ and on each of the last three tests $(p<0.01$ in each case). Figure $2 A$ shows examples of the firing of LE and LFS neurons, and Figure $2 B$ shows the average evoked firing during the first $1 \mathrm{sec}$ after the start of the response to siphon stimulation, which included the peak of the siphon withdrawal on most trials (the average time to peak was $927 \pm 28 \mathrm{msec}$ overall and did not change by $>200 \mathrm{msec}$ during conditioning). Evoked firing of LFS motor neurons changed approximately in parallel with the changes in siphon withdrawal, with paired training producing a significantly greater enhancement of LFS firing than unpaired training overall $\left(F_{(1,24)}\right.$ $=13.51 ; p<0.01)$ and on the last three tests $(p<0.01$ in each case). Moreover, the increase in evoked LFS firing correlated significantly with the increase in siphon withdrawal $(r=0.856$; $p<0.001$ on the final post-test; Fig. $2 C$ ), and pairing did not have any significant additional effect on withdrawal when this correlation was factored out in an analysis of covariance. These results suggest that pairing-specific changes in evoked LFS firing make an important contribution to conditioning of the siphon withdrawal reflex in this preparation.

There was also an increase in evoked firing of LE sensory neurons, with paired training again producing a significantly 


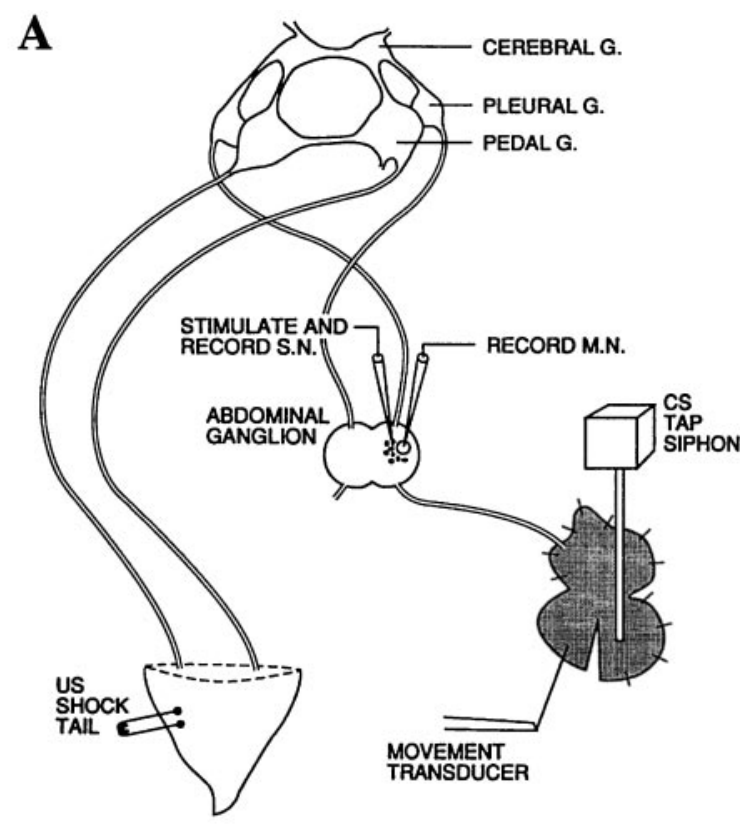

C
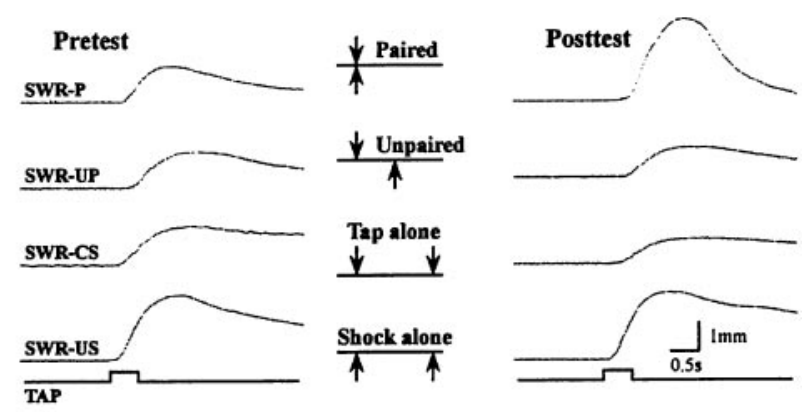

B

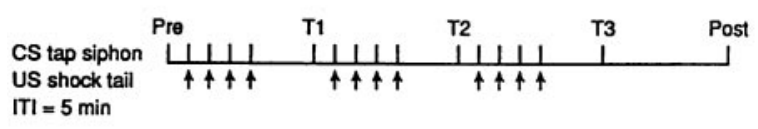

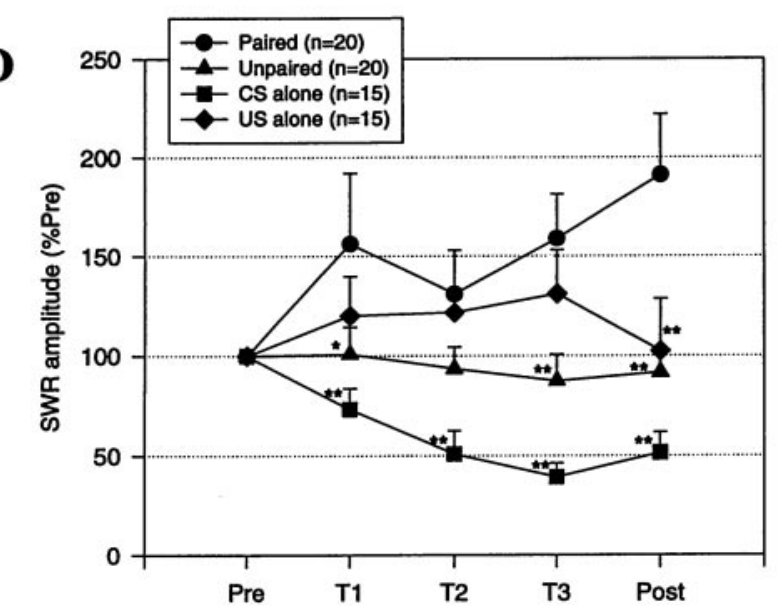

Figure 1. Classical conditioning of the Aplysia siphon withdrawal reflex $(S W R)$ in the simplified preparation. $A$, Experimental preparation. $G$., Ganglion; S.N., sensory neuron; M.N., motor neuron. B, Protocol for paired training. See Materials and Methods for details. ITI, Intertrial interval. C, Examples of the siphon withdrawal produced by a tap to the siphon (the CS) on the pretest and final post-test after either paired $(P)$ training, unpaired $(U P)$ training, training with the CS alone, or training with the US (tail shock) alone. $D$, Average results in experiments such as those shown in $C$. Paired training produced a greater increase in the amplitude of siphon withdrawal than unpaired training, training with the CS alone, or training with the US alone. ${ }^{*} p<0.05 ;{ }^{* *} p<0.01$ compared with paired. Responses have been normalized to the average values on the pretest, which were $3.2 \mathrm{~mm}$ (paired), $2.7 \mathrm{~mm}$ (unpaired), $2.7 \mathrm{~mm}$ (CS alone), and $3.1 \mathrm{~mm}$ (US alone), not significantly different by a one-way ANOVA. The average unconditioned responses to the first tail shock were $7.5 \mathrm{~mm}$ (paired), $5.9 \mathrm{~mm}$ (unpaired), and $7.8 \mathrm{~mm}$ (US alone), also not significantly different.

greater increase than unpaired training overall $\left(F_{(1,20)}=6.16\right.$; $p<0.05)$ and on the last two tests $(p<0.05$ in each case). However, whereas LFS firing and siphon withdrawal increased only after paired training, LE firing increased after either paired or unpaired training. Furthermore, although there was a trend for the changes in LE firing to correlate with the changes in LFS firing $(r=0.26)$ and siphon withdrawal $(r=0.25)$, pairing still had significant effects when these correlations were factored out in analyses of covariance. These results suggest that the increase in LE firing contributes to the changes in LFS firing and siphon withdrawal during conditioning, but that other mechanisms probably also contribute.

Another mechanism that might contribute to conditioning is a change in the pattern of firing of either the LFS or LE cells, which could produce a change in their effectiveness. To examine the pattern of firing, we calculated the average number of spikes in each $100 \mathrm{msec}$ interval after the onset of the response to the tap on each test (Fig. 3). As illustrated in the examples in Figure $2 \mathrm{~A}$ and the average results in Figure 3, the pattern of firing of the LFS cells on the pretest had four components similar to those described previously (Antonov et al., 1999a): a peak at the onset of the tap, a lower level of sustained firing during the tap, a second peak around the offset of the tap, and a gradual decline after the tap. Also, as described previously (Antonov et al., 1999a), evoked firing of the LE cells on the pretest had two components that corresponded to the first two components of LFS firing, so that PSPs from LE cells contributed directly to LFS firing during the tap but only indirectly to LFS firing after the tap. After either paired or unpaired training, there was a substantial increase in firing of the LE cells during and also after the tap, so that PSPs from the LE cells could contribute directly to LFS firing at that time as well. However, there was no significant change in the overall pattern of LE firing, with approximately equal increases in firing in all of the time intervals and no significant interaction involving time in an ANOVA. Similarly, there were no significant changes in the overall pattern of LFS firing. These results suggest that changes in the pattern of firing of either the LE or LFS cells probably do not contribute significantly to the conditioning.

\section{No change in peripheral effectiveness of the motor neurons during conditioning}

In addition to changes in the CNS, changes in the peripheral effectiveness of the motor neurons contribute to dishabituation and sensitization of siphon withdrawal (Antonov et al., 1999a) and classical conditioning of gill withdrawal (Colebrook and Lukowiak, 1988; Lukowiak and Colebrook, 1988) in simplified mantle organ preparations. We therefore investigated whether 

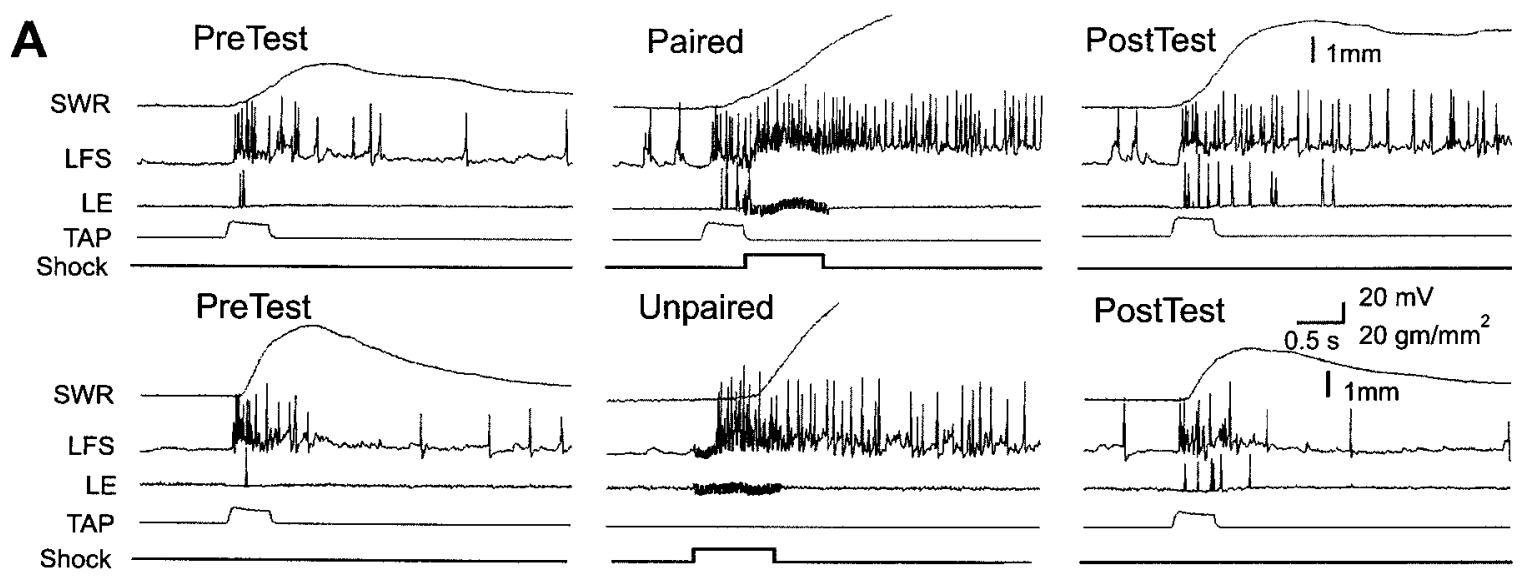

B
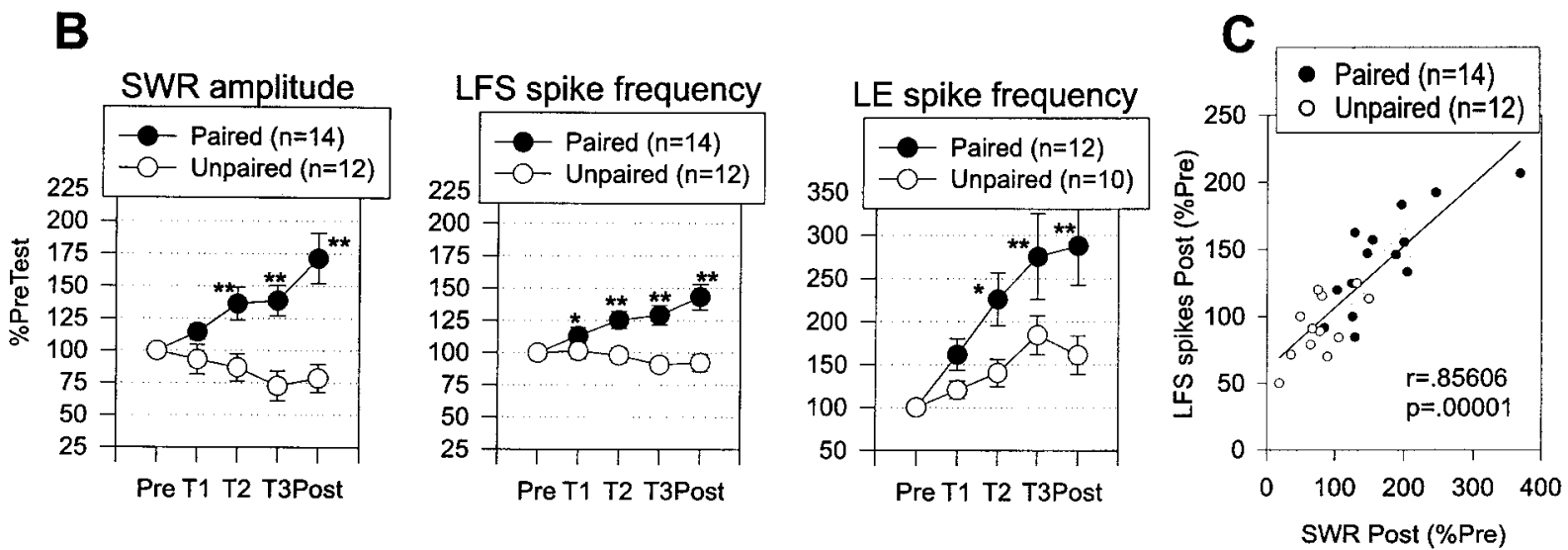

Figure 2. Increase in evoked firing of LFS siphon motor neurons and LE siphon sensory neurons during classical conditioning. $A$, Examples of the behavioral and cellular responses to the conditioned stimulus on the pretest and the final post-test after paired and unpaired training. In some cases the spike amplitudes have been attenuated because of the limited frequency response of the recording. $B$, Average siphon withdrawal and evoked firing of LFS and LE neurons recorded in the same experiments. Paired training produced a greater increase in the amplitude of siphon withdrawal, which was accompanied by a greater increase in evoked firing of the LFS and LE neurons in the first 1 sec. ${ }^{*} p<0.05 ; * *<0.01$ compared with unpaired in this and subsequent figures. The average values on the pretest were $2.4 \mathrm{~mm}$ (paired) and $2.7 \mathrm{~mm}$ (unpaired) for siphon withdrawal, $13.7 \mathrm{~Hz}$ (paired) and 16.3 $\mathrm{Hz}$ (unpaired) for LFS firing, and $5.2 \mathrm{~Hz}$ (paired) and $3.9 \mathrm{~Hz}$ (unpaired) for LE firing, not significantly different by $t$ tests. The average unconditioned responses to the first tail shock were $4.3 \mathrm{~mm}$ (paired) and $4.9 \mathrm{~mm}$ (unpaired), not significantly different. $C$, There was a significant correlation between the increase in siphon withdrawal and the increase in evoked firing of the LFS neurons. The solid line indicates the linear regression, and the dashed lines indicate the $95 \%$ confidence intervals for the regression. $S W R$, Siphon withdrawal reflex.

similar peripheral changes also contribute to classical conditioning of siphon withdrawal by measuring the withdrawal produced by intracellular stimulation of an LFS motor neuron $\sim 30 \mathrm{sec}$ after the siphon tap on each test. As shown in Figure 4, there was a decrease in the withdrawal after either paired or unpaired training and no significant difference between them, although there was a trend for paired training to produce a smaller decrease. There was also no significant correlation between the changes in siphon withdrawal elicited by the LFS stimulation and by siphon stimulation $(r=0.26)$. These results suggest that changes in the peripheral effectiveness of the LFS neurons do not make an important contribution to conditioning in the siphon withdrawal preparation.

In these experiments, the LFS neuron was stimulated intracellularly with a constant current pulse, which produced an approximately constant number of LFS spikes on each test (Fig. 4B), indicating that there was no significant change in the excitability of the motor neuron. There was also no significant change in either the spontaneous firing rate of LFS neurons (Fig. 4B) or their input resistance measured with a hyperpolarizing intracel- lular current pulse $10 \mathrm{sec}$ before the siphon tap (paired mean \pm $\mathrm{SEM}=99.5 \pm 3.8 \% ; n=14$; unpaired mean $\pm \mathrm{SEM}=96.7 \pm$ $3.6 \% ; n=11)$. These results indicate that classical conditioning of the siphon withdrawal reflex is not accompanied by significant changes in the membrane properties of the LFS neurons.

\section{Increase in the complex PSP in LFS motor neurons during conditioning}

To investigate changes in the synaptic input to the LFS motor neurons during conditioning, we hyperpolarized the LFS neuron for a few seconds to prevent it from spiking and recorded the complex PSP produced by the siphon tap on each test (Fig. 5). With the LFS cell effectively removed from the circuit, the average siphon withdrawal on the pretest was reduced by $\sim 30 \%$ compared with experiments in which the LFS cell was not hyperpolarized, which agrees fairly well with previous estimates of the contribution of a single LFS cell to the reflex response in this preparation (Antonov et al., 1999a). Despite the functional removal of the neuron from the circuit, behavioral conditioning was fairly normal, suggesting that firing of the remaining motor neu- 


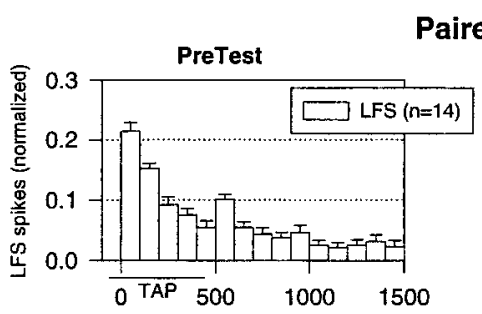

Paired

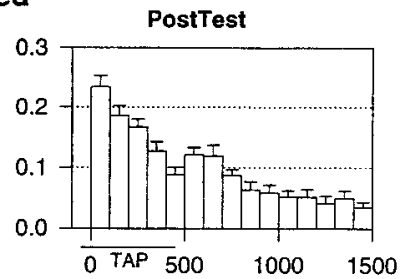

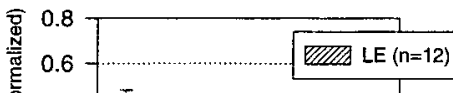
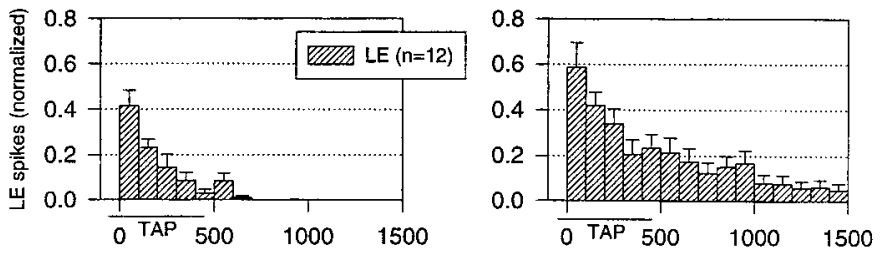

Unpaired
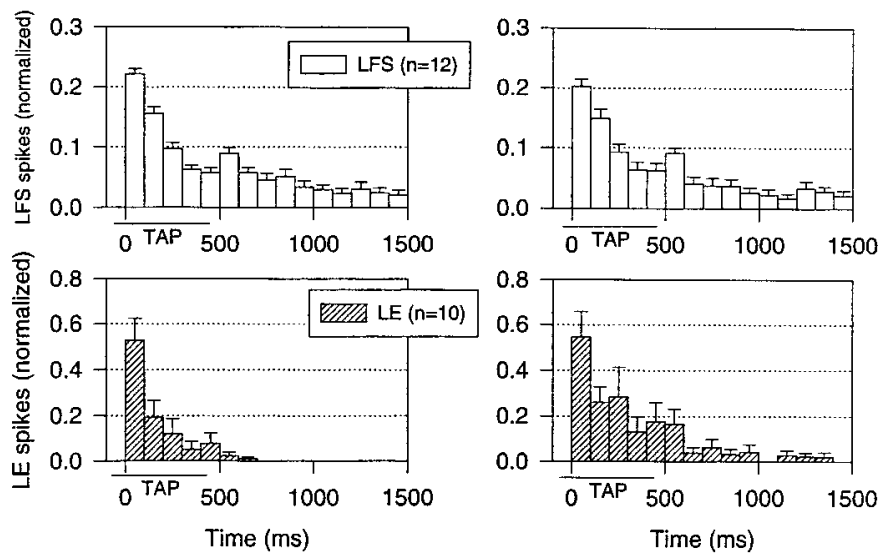

Figure 3. Average pattern of firing of LFS motor neurons and LE sensory neurons on the pretest and final post-test after paired and unpaired training in the same experiments as in Figure 2. The number of spikes in each $100 \mathrm{msec}$ interval has been normalized to the total number of spikes on the pretest in each experiment. The average values on the pretest were 15.8 spikes (paired) and 18.8 spikes (unpaired) for LFS firing and 5.2 spikes (paired) and 3.9 spikes (unpaired) for LE firing, not significantly different. The horizontal bar below the $x$-axis indicates the approximate duration of the siphon tap.

rons undergoes plasticity similar to that of the one that was hyperpolarized.

Because the complex PSP in an LFS neuron has a complicated shape with multiple peaks (Figs. $5 A, 6$ ), we measured the total area under the PSP in the first $1 \mathrm{sec}$ after its onset. As shown in Figure $5 B$, the area of the PSP changed approximately in parallel with the change in siphon withdrawal, with paired training producing a significantly greater increase in the PSP than unpaired training overall $\left(F_{(1,23)}=20.79 ; p<0.001\right)$ and on each test $(p<$ 0.01 in each case). Moreover, the increase in the area of the complex PSP correlated significantly with the increase in siphon withdrawal ( $r=0.643 ; p<0.001$ on the final post-test). These results suggest that changes in synaptic input to the LFS motor neurons make an important contribution to classical conditioning of the siphon withdrawal reflex.

To examine possible changes in the shape of the complex PSP, we calculated the average area in each $50 \mathrm{msec}$ interval after the onset of the response to the tap on each test (Fig. 6). As illustrated in the examples in Figure 5A and the average results in Figure 6, the complex PSP on the pretest had four components similar to those described previously (Antonov et al., 1999a),
A

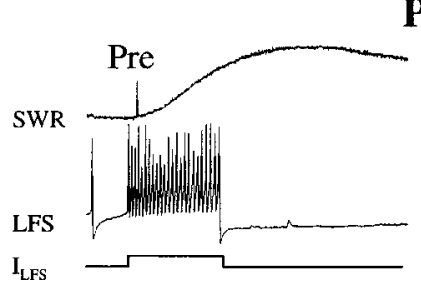

Paired

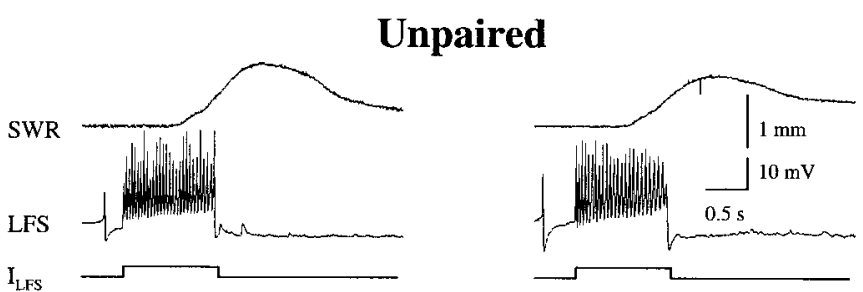

B
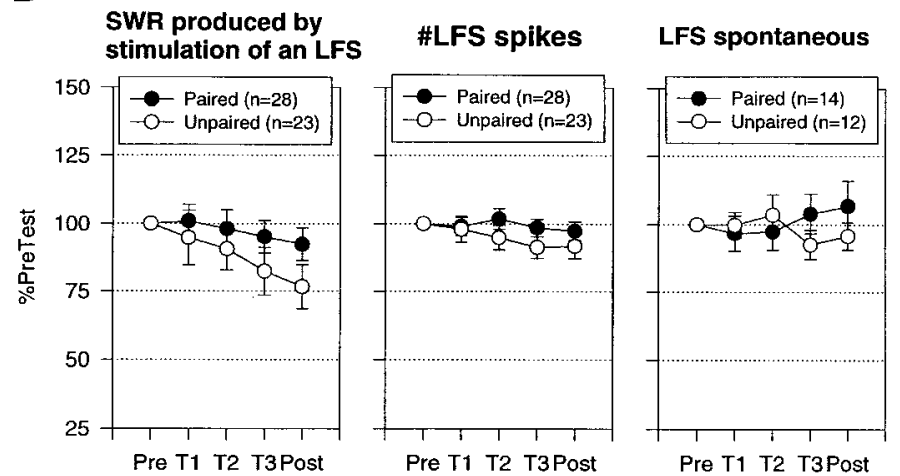

Figure 4. Classical conditioning did not involve significant changes at sites distal to the synapses onto the motor neurons. $A$, Examples of siphon withdrawal produced by constant current intracellular stimulation of an LFS neuron $\left(I_{L F S}\right) 30 \mathrm{sec}$ after the pretest and the final post-test after paired and unpaired training. $B$, Average siphon withdrawal and number of spikes produced by intracellular stimulation of an LFS neuron in experiments like those shown in $A$, as well as the spontaneous firing rate of the LFS neuron $5 \mathrm{sec}$ before each test. There was no significant difference in siphon withdrawal and also no differences in excitability or spontaneous firing of the motor neuron. The average values on the pretest were $0.7 \mathrm{~mm}$ (paired) and $0.8 \mathrm{~mm}$ (unpaired) for siphon withdrawal, 23.1 spikes (paired) and 26.2 spikes (unpaired) for LFS spikes, and $1.6 \mathrm{~Hz}$ (paired) and $1.6 \mathrm{~Hz}$ (unpaired) for LFS spontaneous firing, not significantly different by $t$ tests. $S W R$, Siphon withdrawal reflex.

which correspond to the four components of firing of the motor neuron: a peak at the beginning of the tap, a smaller sustained depolarization during the tap, a second peak around the offset of the tap, and a gradual decline after the tap. There was a significant change in the shape of the complex PSP after paired but not unpaired training $\left(F_{(29,667)}=1.74 ; p<0.01\right.$ for the pairing $\times$ test $\times$ time interaction), with increases in each time interval but a greater increase around the end of the tap. This pairing-specific change in the shape of the complex PSP could in principle contribute to conditioning, although it did not result in a similar change in the pattern of firing of the LFS motor neurons when they were not hyperpolarized (Fig. 3).

\section{Increase in monosynaptic PSPs from on-field LE sensory neurons during conditioning}

The complex PSP in an LFS neuron includes monosynaptic PSPs from identified LE siphon sensory neurons as well as unidentified 
A

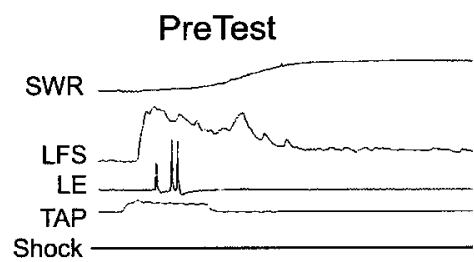

PreTest

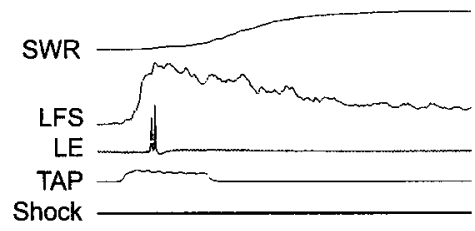

B

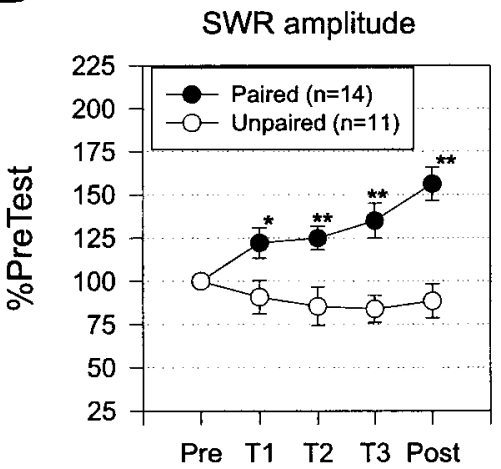

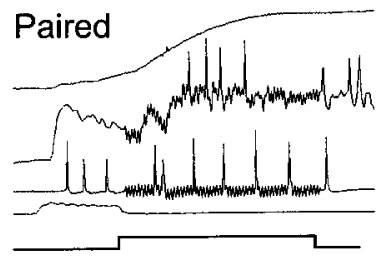

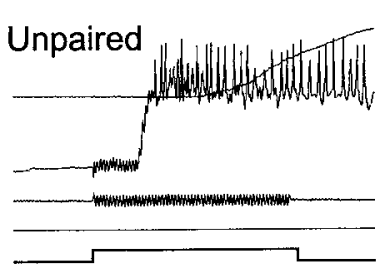

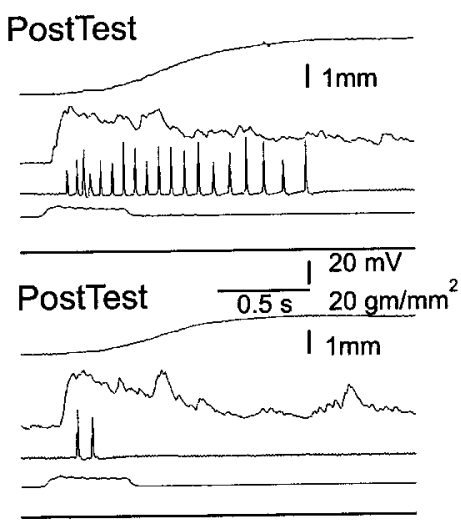

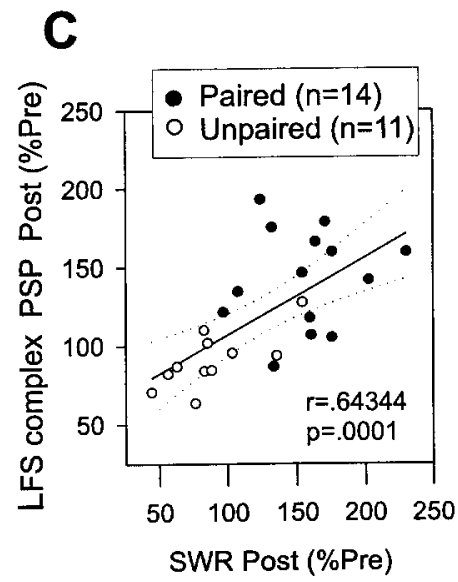

Figure 5. Facilitation of the complex PSP in LFS motor neurons during classical conditioning. $A$, Examples of the complex PSP produced in an LFS motor neuron by the siphon tap on the pretest and the final post-test after paired and unpaired training. In these experiments, the motor neuron was hyperpolarized to approximately $-90 \mathrm{mV}$ for a few seconds to prevent it from firing during the tap. $B$, Average magnitudes of siphon withdrawal and the complex PSP recorded in the same experiments. Paired training produced a greater increase in the amplitude of siphon withdrawal that was accompanied by a greater increase in the area of the complex PSP in the first $1 \mathrm{sec}$ after its onset. The average values on the pretest were $1.8 \mathrm{~mm}$ (paired) and $1.7 \mathrm{~mm}$ (unpaired) for siphon withdrawal, and 36,369 $\mathrm{mVmsec}$ (paired) and 34,516 mVmsec (unpaired) for PSP area, not significantly different by $t$ tests. The average unconditioned responses to the first tail shock were $3.7 \mathrm{~mm}$ (paired) and $4.1 \mathrm{~mm}$ (unpaired), not significantly different. $C$, There was a significant correlation between the increase in the amplitude of siphon withdrawal and the increase in the area of the complex PSP.

sensory neurons (Frost et al., 1997) and a polysynaptic input from excitatory and inhibitory interneurons (Frost and Kandel, 1995). To examine changes in the monosynaptic component from LE neurons during conditioning, we used an intracellular depolarizing current pulse to fire a single action potential in an LE neuron $\sim 10 \mathrm{sec}$ before the siphon tap on each test and measured both the amplitude and area of the unitary, monosynaptic PSP in the LFS neuron (Fig. 7). On average, the area of the monosynaptic PSP on the pretest was $2.8 \pm 0.3 \%$ of the area of the complex PSP produced by siphon stimulation $10 \mathrm{sec}$ later in the same experiments $(n=21)$. When the siphon tap was within the receptive field of the LE cell, it fired on average 4.6 spikes during the tap (Fig. 2), and taps of this strength are thought to activate approximately five LE cells (Byrne et al., 1974; Hickie et al., 1997). These results suggest that if monosynaptic PSPs from the LE cells added linearly, they would contribute $\sim 64 \%$ of the area of the complex PSP, which is in good agreement with the previous estimate by Antonov et al. (1999a) based on similar methods. This is probably an overestimate, because the PSPs do not add linearly as they approach their reversal potential, and they also tend to undergo homosynaptic depression during a burst of spikes in a single sensory neuron (cf. Murphy and Glanzman, 1996).
However, these effects might be partially offset by heterosynaptic facilitation caused by recruitment of modulatory neurons during a siphon tap (Hawkins and Schacher, 1989; Mackey et al., 1989), so that the linear estimate may serve as an approximation.

The LE neurons in these experiments were classified as either on-field if the siphon tap was within the receptive field of the cell and caused it to fire and participate in the reflex or off-field if the tap was outside the receptive field of the cell and did not cause it to fire. Both the amplitude and area of monosynaptic PSPs from on-field LE neurons changed approximately in parallel with changes in the complex PSP and evoked firing of the LFS neurons during conditioning, whereas there were much smaller changes in PSPs from off-field LE neurons. For the on-field LE neurons, paired training produced a significantly greater increase in the monosynaptic PSPs than unpaired training overall (amplitude, $F_{(1,37)}=18.75 ; p<0.001$; area, $\left.F_{(1,37)}=15.60 ; p<0.001\right)$ and on the last three tests $(p<0.01$ in each case). Furthermore, the effect of pairing was significantly different for on- and off-field LE neurons (amplitude, $F_{(1,37)}=8.79 ; p<0.01$; area, $F_{(1,37)}=3.78$; $p<0.05$, one-tailed test for the pairing $\times$ receptive field interaction), with paired training producing significantly greater increases in the PSPs from on- than off-field LE neurons on the final 

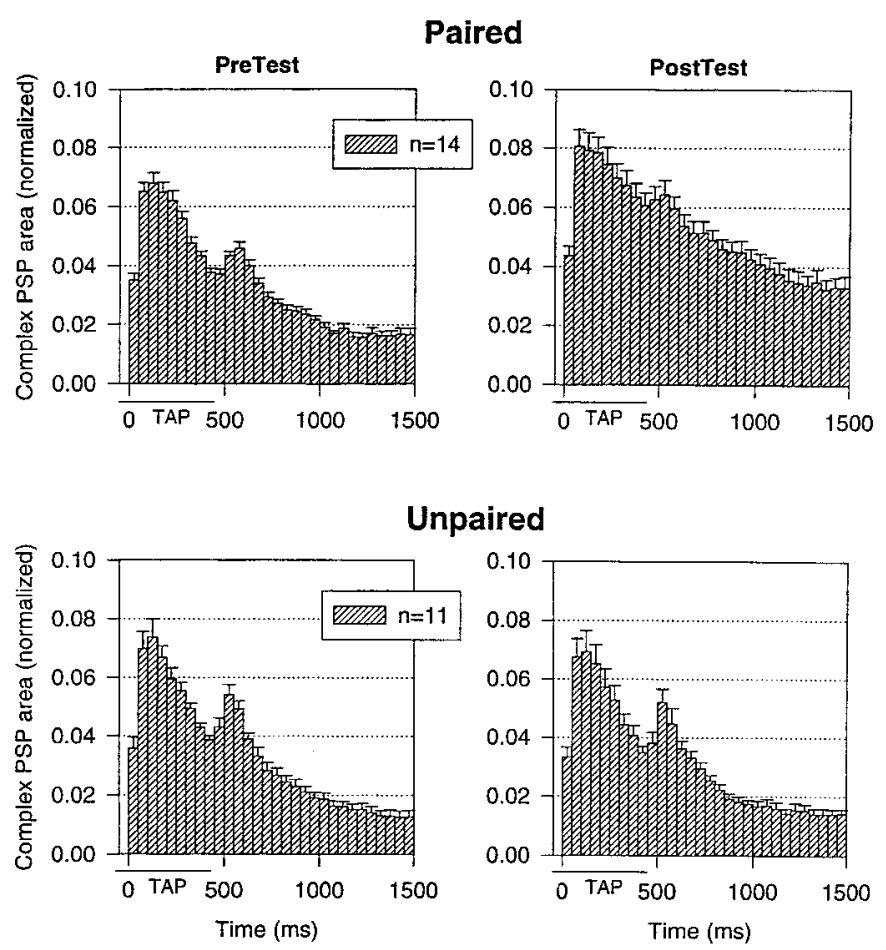

\section{Unpaired}

Figure 6. The average shape of the complex PSP in LFS motor neurons on the pretest and the final post-test after paired and unpaired training in the same experiments as in Figure 5. The PSP in each $50 \mathrm{msec}$ interval has been normalized to the total area on the pretest in each experiment. The average values on the pretest were 44,018 $\mathrm{mVmsec}$ (paired) and 41,132 $\mathrm{mVmsec}$ (unpaired), not significantly different.

post-test $(p<0.05)$. These results are all consistent with the idea that conditioning involves changes in monosynaptic PSPs from LE sensory neurons to LFS motor neurons, and that those changes in turn are attributable to activity-dependent, associative synaptic plasticity, which occurs when spikes in the sensory neuron are temporally paired with the US.

The increase in the area of monosynaptic PSPs from on-field LE neurons correlated significantly with the increases in both siphon withdrawal $(r=0.684 ; p<0.001$ on the final post-test $)$ and LFS firing $(r=0.777 ; p<0.01)$ (Fig. 8). Furthermore, pairing did not have any significant additional effect on LFS firing when this correlation was factored out in an analysis of covariance. By contrast, the increase in the area of PSPs from off-field LE neurons did not correlate significantly with the increases in either siphon withdrawal $(r=0.016)$ or LFS firing $(r=0.203)$. Results on the amplitude of the PSPs were similar (data not shown). These results suggest that increases in monosynaptic PSPs from on-field LE neurons make an important contribution to the increases in LFS firing and siphon withdrawal during conditioning in this preparation.

\section{Increase in input resistance of on-field LE sensory neurons during conditioning}

Cellular analogs of conditioning produce pairing-specific changes in the membrane properties of the LE sensory neurons (Hawkins et al., 1983; Clark et al., 1994; Eliot et al., 1994). These changes are thought to be attributable to a reduction in $\mathrm{K}^{+}$current, which is reflected in an increase in input resistance of the neurons. We therefore investigated changes in the input resistance of the LE neurons by measuring the hyperpolarization produced by an intracellular current pulse $\sim 10$ sec before the monosynaptic PSP
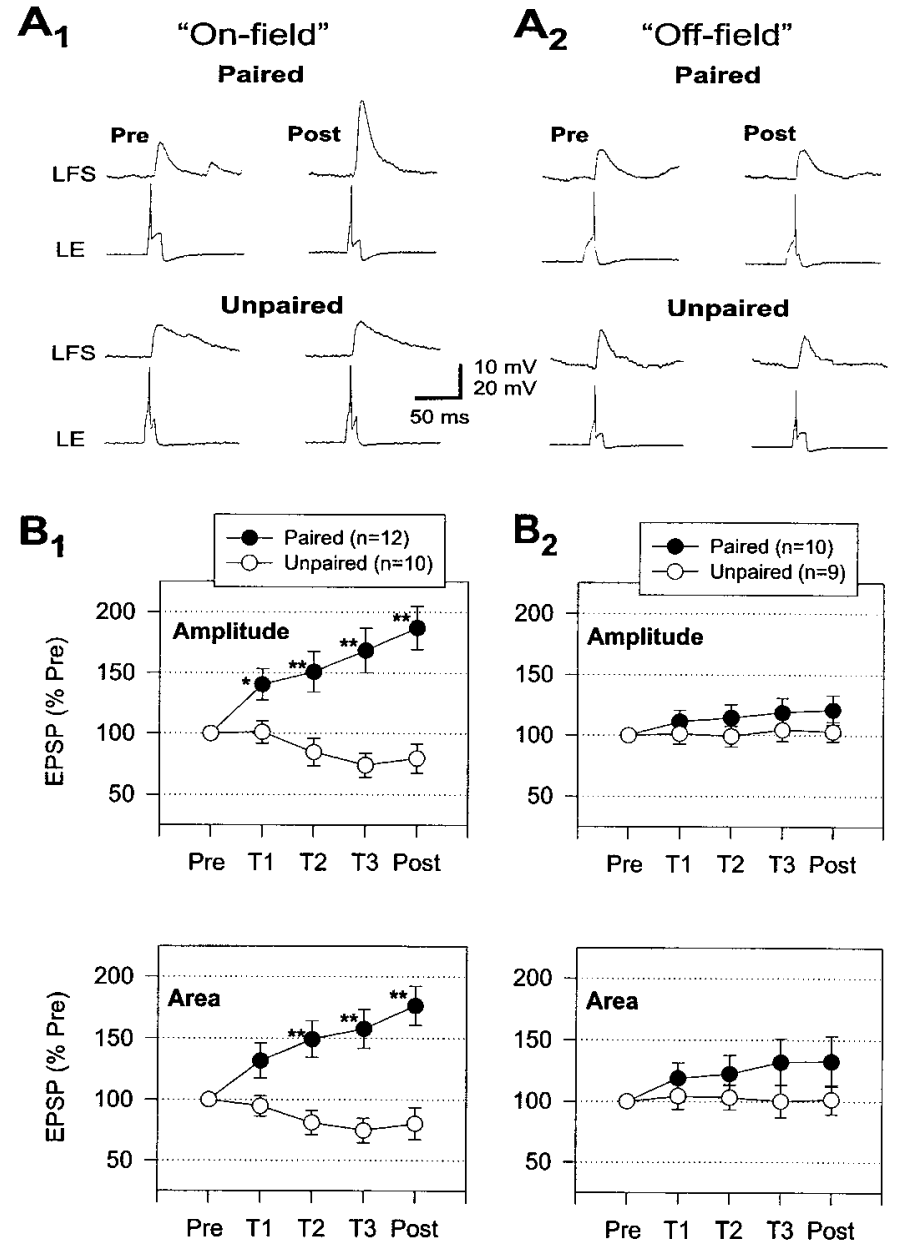

Figure 7. Facilitation of the monosynaptic PSP from an LE neuron to an LFS neuron during classical conditioning. $A$, Examples of the monosynaptic PSP produced in an LFS neuron by intracellular stimulation of an on-field $\left(A_{1}\right)$ and off-field $\left(A_{2}\right)$ LE neuron $\sim 10 \mathrm{sec}$ before the siphon tap on the pretest and the final post-test after paired and unpaired training. $B$, Average modulation of the monosynaptic PSPs during paired and unpaired training. Paired training produced a greater increase than unpaired training in the amplitude and area of PSPs from LE neurons that fired during the siphon tap (on-field; $B_{1}$ ). The increase in PSPs from on-field LE neurons during paired training was also significantly greater than the increase in PSPs from LE neurons that did not fire during the siphon tap (off-field; $B_{2}$ ). The average values on the pretest were $10.8 \mathrm{mV}$ and $820 \mathrm{mVmsec}$ (paired, on-field), $13.0 \mathrm{mV}$ and $1040 \mathrm{mVmsec}$ (unpaired, on-field), $10.6 \mathrm{mV}$ and $633 \mathrm{mVmsec}$ (paired, off-field), and 14.2 $\mathrm{mV}$ and $1031 \mathrm{mVmsec}$ (unpaired, off-field), not significantly different by ANOVAs.

on each test in some of the experiments shown in Figure 7. As shown in the example in Figure $9 A$ and the average results in Figure $9 B$, the input resistance of the LE neurons changed approximately in parallel with changes in the monosynaptic PSPs during conditioning. Paired training produced a significantly greater increase in the input resistance of on-field LE neurons than unpaired training on the final post-test $(p<0.01)$, whereas there was no significant difference for off-field LE neurons. Paired training also produced a significantly greater increase in the input resistance of on- than off-field LE neurons on the final post-test ( $p<0.05$, one-tailed). Moreover, the increase in input resistance of on-field LE neurons correlated significantly with the increase in the area of the monosynaptic PSP $(r=0.695 ; p<0.05$ 


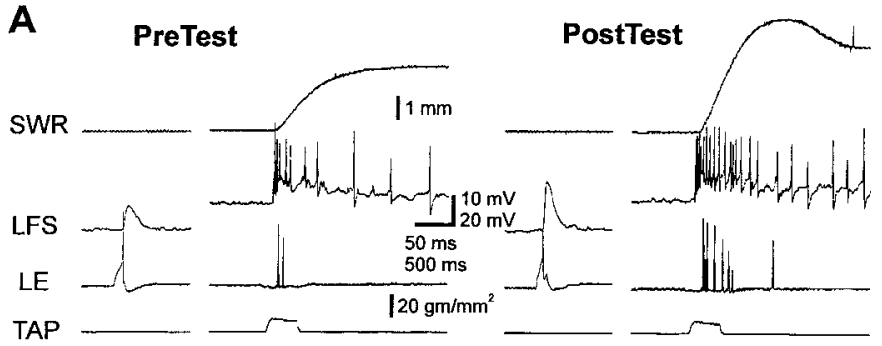

B
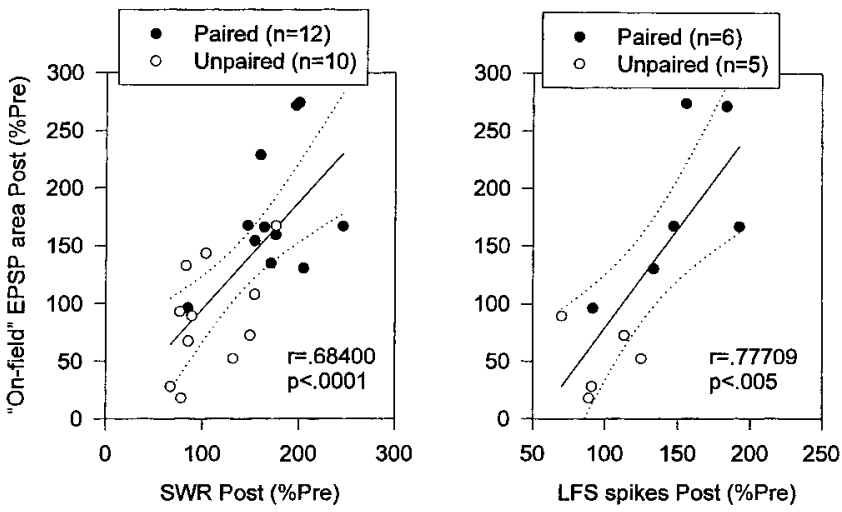

Figure 8. Correlations between on-field monosynaptic PSPs and siphon withdrawal or LFS firing during classical conditioning. $A$, Examples of the monosynaptic PSP recorded $\sim 10 \mathrm{sec}$ before siphon withdrawal and evoked firing of an LFS neuron on the pretest and the final post-test in a single experiment. $B$, There were significant correlations between the increase in the area of on-field monosynaptic PSPs and the increases in the amplitude of siphon withdrawal or number of evoked spikes in an LFS motor neuron. $S W R$, Siphon withdrawal reflex.

on the final post-test; Fig. 9C), and pairing did not have any significant additional effect on the PSP when this correlation was factored out in an analysis of covariance. These results suggest that pairing-specific changes in the membrane properties of onfield LE neurons make an important contribution to changes in the monosynaptic PSPs during conditioning. The increase in input resistance of on-field LE neurons also correlated significantly with the increase in evoked firing of the LE neurons $(r=$ $0.622 ; p<0.05$ ), suggesting that changes in LE membrane properties contribute to changes in evoked LE firing as well.

\section{DISCUSSION}

We have used the simplified siphon withdrawal preparation to analyze cellular mechanisms contributing to classical conditioning. Behavioral conditioning in this preparation is similar to conditioning of siphon withdrawal in intact Aplysia (Carew et al., 1981) and conditioning of gill withdrawal in another simplified preparation (Hawkins et al., 1998), both of which display additional higher-order features that are characteristic of conditioning in vertebrates (Carew et al., 1983; Hawkins et al., 1986, 1989, 1998; Colwill et al., 1988a,b; Walters, 1989). With the siphon withdrawal preparation, it is relatively easy to examine behavioral conditioning while simultaneously monitoring PSPs between identified sensory and motor neurons that contribute to the behavior. Previous studies have estimated that $\sim 55 \%$ of the siphon withdrawal reflex in the simplified preparation is mediated through the CNS, that most of the central component of the reflex
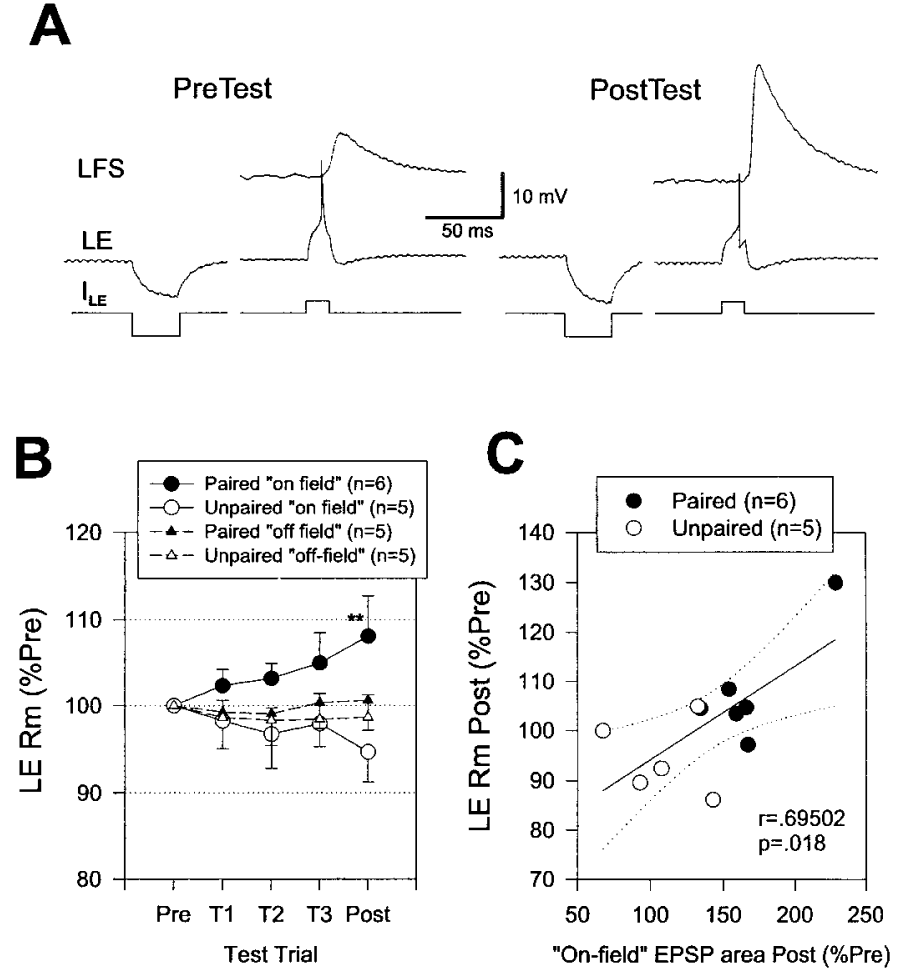

Figure 9. Increase in input resistance of LE sensory neurons during classical conditioning. $A$, Examples of the input resistance of an LE neuron measured with a hyperpolarizing intracellular current pulse $\left(I_{L E}\right)$ $\sim 10 \mathrm{sec}$ before recording the monosynaptic PSP on the pretest and the final post-test in a single experiment. $B$, Average change in input resistance in experiments like the one shown in $A$. Paired training produced a greater increase than unpaired training in the input resistance of on-field LE neurons. There were no significant changes in the input resistance of off-field LE neurons. $C$, There was a significant correlation between the increase in the area of the monosynaptic PSP and the increase in the input resistance of on-field LE neurons. $R m$, Membrane resistance.

is mediated by two or three LFS siphon motor neurons, and that $\sim 60 \%$ of the synaptic input to the LFS neurons is provided by monosynaptic PSPs from LE siphon sensory neurons (Antonov et al., 1999a). Our results are in good agreement with those estimates. In addition, we have found that during conditioning the monosynaptic LE-LFS PSPs change approximately in parallel with complex PSPs in the LFS motor neurons, evoked firing of the LFS neurons, and behavior (Fig. 10). Changes in the monosynaptic PSPs also correlate significantly with changes in LFS firing and behavior. These results provide perhaps the strongest evidence yet obtained in any system that changes in monosynaptic PSPs contribute to associative learning.

We also obtained evidence for two additional mechanisms, although their contribution to conditioning appears to be smaller. First, there was an increase and prolongation of evoked firing of the LE sensory neurons, and this effect was greater after paired than unpaired training (Fig. 2). A prolongation of sensory neuron firing has previously been described for sensitization of the tail withdrawal reflex (Walters et al., 1983) but not for sensitization of the siphon withdrawal reflex (Antonov et al., 1999a). However, the increase in evoked LE firing had low correlations with the increases in LFS firing and siphon withdrawal, and pairing still had significant effects when those correlations were factored out in analyses of covariance. Second, there was a change in the shape of the complex PSP after paired but not unpaired training, with 


\section{SWR amplitude LFS \& LE frequency}

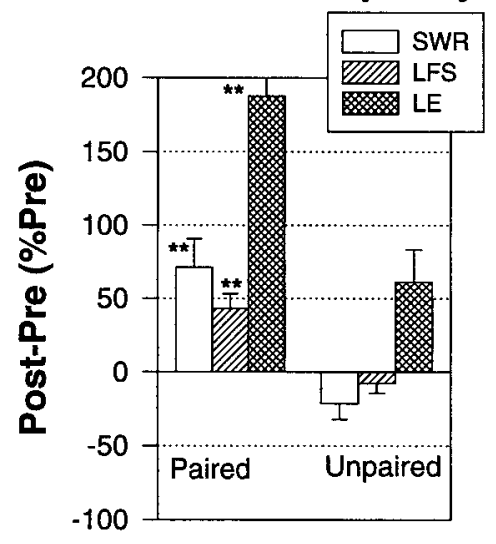

PSP Area $\left(\mathrm{mV}^{\star} \mathrm{ms}\right)$

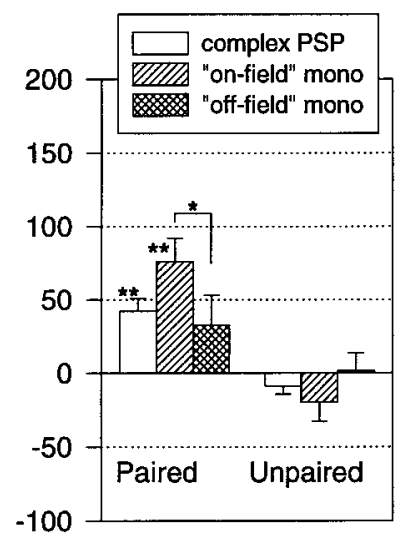

LFS \& LE Rm

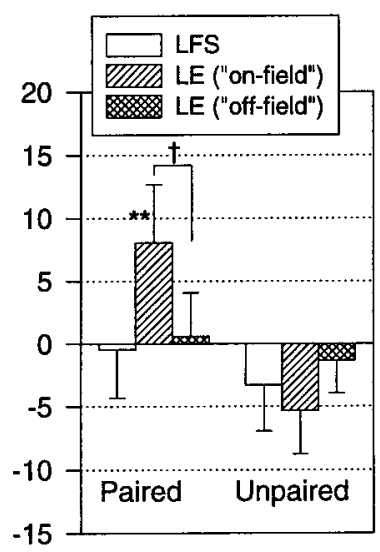

Figure 10. Summary of results of the electrophysiological experiments. The siphon withdrawal reflex $(S W R)$ in the simplified preparation undergoes classical conditioning that is accompanied by pairing-specific increases in evoked firing of both LFS motor neurons and LE sensory neurons, the complex PSP in LFS neurons, the monosynaptic PSP from on-field LE neurons to LFS neurons, and the input resistance of on-field LE neurons $\left(* * p<0.01 ;{ }^{*} p<0.05 ; \dagger p<\right.$ 0.05 , one-tailed compared with either unpaired or off-field). Moreover, there were significant correlations between most of these measures. These results provide direct evidence that conditioning is attributable in part to activitydependent plasticity of monosynaptic sensory neuron-motor neuron PSPs. the largest increase in the PSP occurring around the end of the tap (Fig. 6). A similar change occurs during sensitization in the siphon withdrawal preparation (Antonov et al., 1999a) and might be attributable to either plasticity in the interneurons or changes in short-term plasticity (metaplasticity) of monosynaptic PSPs from LE sensory neurons during the siphon tap (Fischer et al., 1997; Phares and Byrne, 1999). However, this change in the shape of the complex PSP did not result in a similar change in the pattern of firing of the LFS motor neurons when they were not hyperpolarized (Fig. 3).

In similar experiments on conditioning in a simplified gill withdrawal preparation, Colebrook and Lukowiak (1988) and Lukowiak and Colebrook (1988) found a dissociation between firing of the motor neuron and behavior, which they attributed to a change in the peripheral effectiveness of the gill motor neurons. We found no significant change in the peripheral effectiveness of the LFS siphon motor neurons after conditioning, although there is such a change shortly $(2.5 \mathrm{~min})$ after sensitization in the simplified siphon withdrawal preparation (Antonov et al., 1999a). Such peripheral effects may have been more important in the gill withdrawal preparation of Colebrook and Lukowiak (1988) and Lukowiak and Colebrook (1988), because part of the reflex in that preparation is mediated through peripheral ganglia (the genital and gill ganglia). By contrast, most of the peripheral component of the siphon withdrawal reflex is mediated through direct synaptic connections from siphon sensory neurons to peripheral siphon motor neurons, which undergo many of the same types of plasticity as the central synapses of the sensory neurons (Bailey et al., 1979; Clark and Kandel, 1984).

Lukowiak (1986) also observed an increase in PSPs from offfield sensory neurons during conditioning in a simplified gill withdrawal preparation. The mechanism of this effect is not known, but it could involve a pairing-specific enhancement of the effectiveness of the US (Hawkins et al., 1983). There was a similar trend in our results (Fig. $7 B$ ), although it was not significant. However, in addition to this modest increase in PSPs from offfield LE neurons, we observed a significantly greater pairingspecific increase in monosynaptic PSPs from on-field LE neurons (Fig. 7A). This difference between on- and off-field LE neurons is consistent with either of two known activity-dependent mechanisms of associative synaptic plasticity: activity-dependent enhancement of presynaptic facilitation, which occurs when presynaptic spike activity is temporally paired with a facilitatory neurotransmitter (Hawkins et al., 1983, 1993; Walters and Byrne,
1983), and Hebbian long-term potentiation, which occurs when presynaptic spike activity is temporally paired with postsynaptic depolarization (Kelso et al., 1986; Wigström et al., 1986). Both of these types of plasticity occur at Aplysia sensory-motor neuron synapses in isolated cell culture (Eliot et al., 1994; Lin and Glanzman, 1994a,b; Bao et al., 1997, 1998; Schacher et al., 1997). They could also both occur during behavioral conditioning of the siphon withdrawal reflex, because the siphon tap causes spike activity in the LE sensory neurons, and the tail shock causes both the release of facilitatory neurotransmitters (Hawkins and Schacher, 1989; Mackey et al., 1989) and depolarization of the LFS motor neurons.

It will now be interesting to examine the roles of these two activity-dependent mechanisms in conditioning of the siphon withdrawal reflex. Preliminary evidence suggests that they may both contribute. On the one hand, postsynaptic manipulations that block Hebbian long-term potentiation, such as BAPTA injection and NMDA receptor antagonists, also reduce a cellular analog of conditioning in the isolated nervous system (Murphy and Glanzman, 1996, 1997, 1999) and behavioral conditioning in the simplified preparation (Antonov et al., 1999b). However, those manipulations may also block activity-dependent enhancement of presynaptic facilitation (Bao et al., 1998). On the other hand, the changes in the monosynaptic PSPs during conditioning are accompanied by and correlated with changes in the input resistance of the LE sensory neurons (Fig. 9). The changes in input resistance are clearly presynaptic and are consistent with activity-dependent presynaptic facilitation, which is thought to involve a pairing-specific decrease in $\mathrm{K}^{+}$current, leading to broadening of action potentials and enhanced transmitter release from the sensory neurons (Hawkins et al., 1983, 1993). Such a decrease in $\mathrm{K}^{+}$current could also account for the pairing-specific increase in evoked firing of the sensory neurons (Fig. 2). Changes in input resistance and evoked firing of the LE sensory neurons are not incompatible with Hebbian long-term potentiation and might be expected if a postsynaptic site of induction is accompanied by a presynaptic site of expression. Indeed, we have recently found that the pairing-specific increases in evoked firing and input resistance of the LE neurons are blocked by injection of BAPTA into the LFS neuron, consistent with the idea that conditioning involves a hybrid presynaptic and postsynaptic mechanism and retrograde signaling (Antonov et al., 2000). Regardless of the exact cellular mechanism, however, our present results provide the most direct evidence so far that plasticity of 
monosynaptic sensory neuron-motor neuron PSPs contributes to classical conditioning of the siphon withdrawal reflex and support the idea that synaptic plasticity is a mechanism of learning and memory more generally.

\section{REFERENCES}

Antonov I, Kandel ER, Hawkins RD (1999a) The contribution of facilitation of monosynaptic PSPs to dishabituation and sensitization of the Aplysia siphon withdrawal reflex. J Neurosci 19:10438-10450.

Antonov I, Antonova I, Hawkins RD (1999b) Activity-dependent facilitation of monosynaptic sensory neuron-motor neuron PSPs contributes to classical conditioning of the Aplysia siphon-withdrawal reflex in a simplified preparation. Soc Neurosci Abstr 25:1129.

Antonov I, Kandel ER, Hawkins RD (2000) Contribution of pre- and postsynaptic mechanisms to activity-dependent facilitation during classical conditioning of the Aplysia siphon-withdrawal reflex. Soc Neurosci Abstr 26:1523.

Bailey CH, Castellucci VF, Koester J, Kandel ER (1979) Cellular studies of peripheral neurons in siphon skin of Aplysia californica. J Neurophysiol 42:530-557.

Bao J-X, Kandel ER, Hawkins RD (1997) Involvement of pre- and postsynaptic mechanisms in posttetanic potentiation at Aplysia synapses. Science 275:969-973.

Bao J-X, Kandel ER, Hawkins RD (1998) Involvement of presynaptic and postsynaptic mechanisms in a cellular analog of classical conditioning at Aplysia sensory-motor neuron synapses in isolated cell culture. J Neurosci 18:458-466.

Byrne J (1987) Cellular analysis of associative learning. Physiol Rev 6:329-439.

Byrne JH, Castellucci V, Kandel ER (1974) Receptive fields and response properties of mechanoreceptor neurons innervating skin and mantle shelf of Aplysia. J Neurophysiol 37:1041-1064.

Carew TJ, Sahley CL (1986) Invertebrate learning and memory: from behavior to molecules. Annu Rev Neurosci 9:435-487.

Carew TJ, Walters ET, Kandel ER (1981) Classical conditioning in a simple withdrawal reflex in Aplysia californica. J Neurosci 1:1426-1437.

Carew TJ, Hawkins RD, Kandel ER (1983) Differential classical conditioning of a defensive withdrawal reflex in Aplysia californica. Science 219:397-400.

Carew TJ, Hawkins RD, Abrams TW, Kandel ER (1984) A test of Hebb's postulate at identified synapses which mediate classical conditioning in Aplysia. J Neurosci 4:1217-1224.

Clark GA, Kandel ER (1984) Branch-specific heterosynaptic facilitation in Aplysia siphon sensory cells. Proc Natl Acad Sci USA 81:2577-2581.

Clark GA, Hawkins RD, Kandel ER (1994) Activity-dependent enhancement of presynaptic facilitation provides a cellular mechanism for the temporal specificity of classical conditioning in Aplysia. Learn Mem 1:243-257.

Cohen TE, Kaplan SW, Kandel ER, Hawkins RD (1997) A simplified preparation for relating cellular events to behavior: mechanisms contributing to habituation, dishabituation, and sensitization of the Aplysia gill-withdrawal reflex. J Neurosci 17:2886-2899.

Colebrook E, Lukowiak K (1988) Learning by the Aplysia model system: lack of correlation between gill and gill motor neuron responses. J Exp Biol 135:422-429.

Colwill RM, Absher RA, Roberts ML (1988a) Context US learning in Aplysia californica. J Neurosci 8:4434-4439.

Colwill RM, Absher RA, Roberts ML (1988b) Conditional discrimination learning in Aplysia californica. J Neurosci 8:4440-4444.

Eliot LS, Hawkins RD, Kandel ER, Schacher S (1994) Pairing-specific, activity-dependent presynaptic facilitation at Aplysia sensory-motor neuron synapses in isolated cell cultures. J Neurosci 14:368-383.

Fischer TM, Blazie DE, Priver NA, Carew TJ (1997) Metaplasticity at identified inhibitory synapses in Aplysia. Nature 389:860-865.

Frost L, Kaplan SW, Cohen TE, Henzi V, Kandel ER, Hawkins RD (1997) A simplified preparation for relating cellular events to behavior: Contribution of LE and unidentified siphon sensory neurons to mediation and habituation of the Aplysia gill and siphon withdrawal reflex. J Neurosci 17:2900-2913.

Frost WN, Kandel ER (1995) Structure of the network mediating siphon-elicited siphon withdrawal in Aplysia. J Neurophysiol 73:2413-2427.

Hawkins RD (1997) LTP and learning: let's stay together. Behav Brain Sci 20:620-621.

Hawkins RD, Schacher S (1989) Identified facilitator neurons L29 and L28 are excited by cutaneous stimuli used in dishabituation, sensitization, and classical conditioning of Aplysia. J Neurosci 9:4236-4245.

Hawkins RD, Abrams TW, Carew TJ, Kandel ER (1983) A cellular mechanism of classical conditioning in Aplysia: activity-dependent amplification of presynaptic facilitation. Science 219:400-415.

Hawkins RD, Carew TJ, Kandel ER (1986) Effects of interstimulus interval and contingency on classical conditioning of the Aplysia siphon withdrawal reflex. J Neurosci 6:1695-1701.
Hawkins RD, Lalevic N, Clark GA, Kandel ER (1989) Classical conditioning of the Aplysia siphon-withdrawal reflex exhibits response specificity. Proc Natl Acad Sci USA 86:7620-7624.

Hawkins RD, Kandel ER, Siegelbaum SA (1993) Learning to modulate transmitter release: themes and variations in synaptic plasticity. Annu Rev Neurosci 16:625-665.

Hawkins RD, Greene W, Kandel ER (1998) Classical conditioning, differential conditioning, and second-order conditioning of the Aplysia gill-withdrawal reflex in a simplified mantle organ preparation. Behav Neurosci 112:636-645.

Hickie C, Cohen LB, Balaban PM (1997) The synapse between LE sensory neurons and gill motoneurons makes only a small contribution to the Aplysia gill-withdrawal reflex. Eur J Neurosci 9:627-636.

Kelso SR, Ganong AH, Brown TH (1986) Hebbian synapses in hippocampus. Proc Natl Acad Sci USA 83:5326-5330.

Lin XY, Glanzman DL (1994a) Long-term potentiation of Aplysia sensorimotor synapses in cell culture: regulation by postsynaptic voltage. Proc R Soc Lond [Biol] 255:113-118.

Lin XY, Glanzman DL (1994b) Hebbian induction of long-term potentiation of Aplysia sensorimotor synapses: partial requirement for activation of a NMDA-related receptor. Proc R Soc Lond [Biol] 255:215-221.

Lin XY, Glanzman DL (1997) Effect of interstimulus interval on pairing-induced LTP of Aplysia sensorimotor synapses in cell culture. J Neurophysiol 77:667-674.

Lukowiak K (1986) In vitro classical conditioning of a gill withdrawal reflex in Aplysia: neural correlates and possible neural mechanisms. J Neurobiol 17:83-101.

Lukowiak K, Colebrook E (1988) Classical conditioning alters the efficacy of identified gill motor neurons in producing gill withdrawal movements in Aplysia. J Exp Biol 140:273-285.

Mackey SL, Kandel ER, Hawkins RD (1989) Identified serotonergic neurons LCB1 and RCB1 in the cerebral ganglia of Aplysia produce presynaptic facilitation of siphon sensory neurons. J Neurosci 9:4227-4235.

Mayford MA, Bach ME, Huang Y-Y, Wang L, Hawkins RD, Kandel ER (1996) Control of memory formation through regulated expression of a CaMKII transgene. Science 274:1678-1683.

Murphy GG, Glanzman DL (1996) Enhancement of sensorimotor connections by conditioning-related stimulation in Aplysia depends on postsynaptic $\mathrm{Ca}^{2+}$. Proc Natl Acad Sci USA 93:9931-9936.

Murphy GG, Glanzman DL (1997) Mediation of classical conditioning in Aplysia californica by long-term potentiation of sensorimotor synapses. Science 278:467-471.

Murphy GG, Glanzman DL (1999) Cellular analog of differential classical conditioning in Aplysia: disruption by the NMDA receptor antagonist DL-2-amino-5-phosphono-valerate. J Neurosci 19:10595-10602.

Perlman AJ (1979) Central and peripheral control of siphon-withdrawal reflex in Aplysia californica. J Neurophysiol 42:510-529.

Phares GA, Byrne JH (1999) Differential modulation of Aplysia sensorimotor EPSPs during bursts of sensory neuron action potentials. Soc Neurosci Abstr 25:1611.

Ramon y Cajal S (1911) Histologie du systeme nerveux de l'homme et des vertebres. Paris: Maloine.

Rogan MT, Staubli UV, LeDoux JE (1997) Fear conditioning induces associative long-term potentiation in the amygdala. Nature 390:604-607.

Schacher S, Wu F, Sun Z-Y (1997) Pathway-specific synaptic plasticity: activity-dependent enhancement and suppression of long-term heterosynaptic facilitation at converging inputs on a single target. J Neurosci 17:597-606.

Sherrington CS (1906) The integrative action of the nervous system. New Haven, CT: Yale UP.

Tsien JZ, Huerta PT, Tonegawa S (1996) The essential role of hippocampal CA1 NMDA receptor-dependent synaptic plasticity in spatial memory. Cell 87:1327-1338.

Walters ET (1989) Transformation of siphon responses during conditioning of Aplysia suggests a model of primitive stimulus-response association. Proc Natl Acad Sci USA 86:7616-7619.

Walters ET, Byrne JH (1983) Associative conditioning of single sensory neurons suggests a cellular mechanism for learning. Science 219:405-408.

Walters ET, Byrne JH, Carew TJ, Kandel ER (1983) Mechanoafferent neurons innervating tail of Aplysia. II. Modulation by sensitizing stimuli. J Neurophysiol 50:1543-1559.

Wigström H, Gustafsson B, Huang Y-Y, Abraham WC (1986) Hippocampal long-lasting potentiation is induced by pairing single afferent volley with intracellularly injected depolarizing current pulses. Acta Physiol Scand 126:317-319.

Zamanillo D, Sprengel R, Hvalby O, Jensen V, Burnashev N, Rozov A, Kaiser KM, Koster HJ, Borchardt T, Worley P, Lubke J, Frotscher M, Kelly PH, Sommer B, Andersen P, Seeburg PH, Sakmann B (1999) Importance of AMPA receptors for hippocampal synaptic plasticity but not for spatial learning. Science 284:1805-1811. 